\title{
INDUÇÃO DE ESTRESSE MICROBIANO POR CHOQUE TÉRMICO PARA REDUÇÃO DO DESCARTE DE LODO EM LODOS ATIVADOS TRATANDO EFLUENTE DE REFINARIA
}

\author{
T. M. S. de CASTRO ${ }^{1}$, J. P. G. L. MACHADO ${ }^{2}$, V. M. F. ALEXANDRE ${ }^{2}$, V. M. J. \\ SANTIAGO $^{3}$, A. C. F. P. de CERQUEIRA ${ }^{3}$, M. C. CAMMAROTA $^{2}$ \\ ${ }^{1}$ Universidade do Grande Rio \\ ${ }^{2}$ Universidade Federal do Rio de Janeiro \\ ${ }^{3}$ Centro de Pesquisas da Petrobras \\ E-mail para contato: christe@eq.ufrj.br
}

\begin{abstract}
RESUMO - Um dos maiores problemas ambientais e econômicos nas estações de tratamento de efluentes que utilizam o sistema de Lodos Ativados é a elevada produção de lodo de excesso, que se agrava nas refinarias de petróleo devido ao elevado volume de efluentes tratado. Dentre as técnicas existentes para redução de lodo está o choque térmico, que pode induzir a síntese de proteínas de estresse e reduzir a energia direcionada para o crescimento celular. Na operação em batelada deste estudo, o aquecimento de todo o conteúdo do reator a $40^{\circ} \mathrm{C}$ por $20 \mathrm{~min}$, três vezes ao dia, levou a um descarte de lodo $28 \%$ menor que no reator Controle (sem aquecimento). Porém, quando se promoveu um aumento imediato na temperatura do reator e manteve-se a mesma a $40^{\circ} \mathrm{C}$ por 20 e 40 min, não foi observada diferença significativa no descarte. Operando em regime contínuo, com uma fração do licor misto sendo continuamente recirculada por um banho a $40^{\circ} \mathrm{C}$ (com tempo de retenção de 20 e $12 \mathrm{~min}$ ) antes de retornar ao reator, também não foi observada diferença no descarte de lodo. Esses resultados mostram que as condições empregadas para o aumento da temperatura influenciam os resultados obtidos.
\end{abstract}

\section{INTRODUÇÃO}

Um dos processos mais utilizados no tratamento de efluentes, inclusive nas refinarias de petróleo, é o de Lodos Ativados. Contudo, este processo apresenta como desvantagem uma elevada produção de lodo de excesso, que deve ser devidamente tratado e em seguida encaminhado para disposição em aterros industriais (Ma et al., 2012; Foladori et al., 2010). No Brasil, essa questão é agravada com a implementação da Política Nacional de Resíduos Sólidos (Brasil, 2010). Sua premissa básica é a prevenção da geração de resíduos, seguida da redução da quantidade, reaproveitamento, tratamento e, só então, disposição final. $\mathrm{O}$ 
problema é também de cunho econômico, pois o custo com o gerenciamento desse lodo pode ser de até $60 \%$ do custo total de operação de uma planta de tratamento (Foladori et al., 2010).

Algumas modificações no processo podem ser implementadas para reduzir a geração de lodo, como utilizar aeração prolongada e carga mássica reduzida (MetCalf \& Eddy, 2003; von Sperling, 2002). As refinarias brasileiras da Petrobras que tratam os efluentes por Lodos Ativados já produzem naturalmente menos lodo por utilizarem essas condições. Contudo, a geração de efluentes em uma refinaria é bastante elevada, pois o consumo de água é elevado, sendo aproximadamente 1:1 em termos de volume de petróleo processado (Petrobras, 2012). Assim, o problema da geração de lodo se agrava e a redução de sua geração e descarte se torna uma necessidade.

O tratamento térmico do lodo consiste no aquecimento do lodo a temperaturas moderadas $\left(<100^{\circ} \mathrm{C}\right)$ ou altas (até $\left.220^{\circ} \mathrm{C}\right)$ e, dependendo da combinação temperatura e tempo, pode produzir diversos efeitos, tais como quebra da estrutura do lodo, desagregação dos flocos biológicos, solubilização do lodo, lise celular e liberação de constituintes intracelulares. A combinação dos parâmetros temperatura e tempo também pode levar à redução da geração de lodo de excesso (Foladori et al., 2010). Em temperaturas mais baixas, tais como $40^{\circ} \mathrm{C}$, a solubilização do lodo é muito reduzida (Foladori et al., 2010). Porém, o aumento da temperatura pode induzir também o estresse microbiano, juntamente com a síntese das proteínas de estresse. De acordo com Bott e Love (2001) e Enzo Life Sciences (2012), quando ocorre um aumento relevante de temperatura, todos os organismos agem da mesma forma: suas células produzem rapidamente um grupo seleto de proteínas denominadas proteínas de choque térmico (HSPs). O acúmulo dessas proteínas garante proteção às células, permitindo sua sobrevivência (Enzo Life Sciences, 2012; Han et al., 2008), porém o crescimento fica limitado, pois a reserva energética é utilizada para manutenção celular.

Com isso, o objetivo deste estudo foi avaliar a redução do descarte de lodo no tratamento de efluente de refinaria de petróleo por Lodos Ativados, operando em bateladas sequenciais e em modo contínuo, com e sem tratamento térmico, de modo a verificar a viabilidade desta alternativa para minimizar um dos maiores problemas ambientais e econômicos atuais nas estações de tratamento.

\section{MATERIAL E MÉTODOS}

\subsection{Origem do Efluente e do Lodo}

Para a operação dos biorreatores foi utilizada uma corrente de efluente proveniente de uma refinaria de petróleo, denominada Água Ácida (DQO $1826 \pm 598 \mathrm{mg} / \mathrm{L}$ ). Por problemas de operação, foram utilizadas também duas correntes provenientes de outra refinaria, denominadas Água Ácida (DQO $1463 \pm 687 \mathrm{mg} / \mathrm{L}$ ) e Água Oleosa (DQO $331 \pm 144 \mathrm{mg} / \mathrm{L}$ ). Todos os efluentes foram coletados em bombonas plásticas de $20 \mathrm{~L}$ e armazenados à temperatura ambiente até o momento do uso.

Para reduzir o consumo de efluentes da refinaria, foi utilizado também um efluente sintético concentrado (DQO $24860 \pm 1407 \mathrm{mg} / \mathrm{L}$ ) composto por substâncias tipicamente encontradas nos efluentes de refinarias de petróleo, cuja composição encontra-se na Tabela 1. A elaboração deste efluente sintético se baseou na composição proposta por Brookes (2005), 
com modificações. Alguns componentes da formulação foram retirados neste estudo para reduzir a exposição dos técnicos de laboratório a substâncias muito tóxicas e a concentração de $\mathrm{NaCl}$ foi ajustada para um valor de salinidade próximo ao encontrado nas refinarias Petrobras $\left(600 \mathrm{mg} \mathrm{Cl}^{-} / \mathrm{L}\right)$. No preparo da alimentação dos reatores, o efluente sintético concentrado era diluído de modo a contribuir com metade da DQO desejada.

\begin{tabular}{ll} 
Tabela 1 - Composição do efluente sintético concentrado utilizado \\
\hline Composto & Concentração (mg/L) \\
\hline Tolueno & 190 \\
Etilbenzeno & 40 \\
Xileno & 100 \\
Naftaleno & 17 \\
Fenol & 250 \\
Ácido acético & 280 \\
Ácido propiônico & 70 \\
Ácido butírico & 20 \\
Etanol & 13000 \\
Etilenoglicol & 1580 \\
$\mathrm{NaCl}_{\mathrm{Uréia}}$ & 9887 \\
$\mathrm{Na}_{2} \mathrm{HPO}_{4} \cdot 12 \mathrm{H}_{2} \mathrm{O}$ & 2140 \\
$\mathrm{KH}_{2} \mathrm{PO}_{4}$ & 2960 \\
\hline
\end{tabular}

O lodo utilizado como inóculo dos biorreatores foi proveniente de uma refinaria de petróleo. Por ser um lodo centrifugado e, portanto, pastoso, foi caracterizado em termos de massa de sólidos por massa úmida, apresentando $114 \mathrm{mg} \mathrm{ST/g}$ de amostra úmida e $74 \mathrm{mg}$ $\mathrm{SV} / \mathrm{g}$ de amostra úmida. O lodo foi coletado em latas de alumínio protegidas com papel e armazenado a $4^{\circ} \mathrm{C}$ até o momento do uso.

\subsection{Operação dos Biorreatores - Batelada}

Condição 1. Inicialmente, dois biorreatores operaram simultaneamente em bateladas sequenciais. Os biorreatores consistiam de béqueres de vidro de $1 \mathrm{~L}$ (600 mL de volume útil) e introdução de ar comprimido através de um difusor poroso e agitação magnética a fim de garantir um fornecimento adequado de oxigênio e a homogeneidade da suspensão de efluente $(300 \mathrm{~mL})$ e lodo $(300 \mathrm{~mL})$. A alimentação dos biorreatores consistia da corrente de Água Ácida diluída em água destilada de modo a apresentar DQO de $1000 \mathrm{mg} / \mathrm{L}$. A alimentação era suplementada com uma solução de fósforo (40,42 g Na $2 \mathrm{HPO}_{4} .12 \mathrm{H}_{2} \mathrm{O} / \mathrm{L}$ e $6,58 \mathrm{~g} \mathrm{KH}_{2} \mathrm{PO}_{4} / \mathrm{L}$ ) de modo a manter a relação DQO:P em 100:1. Todos os dias, com exceção dos finais de semana, a agitação e aeração eram desligadas e, após a sedimentação do lodo, todo o sobrenadante do reator $(300 \mathrm{~mL})$ era substituído por alimentação nova, simulando um TRH de $24 \mathrm{~h}$. Antes da troca de meio, $30 \mathrm{~mL}$ do licor misto eram retirados para manter uma idade do lodo de 20 d e para análise de pH, DQO centrifugada, sólidos suspensos e sólidos sedimentáveis. $\mathrm{O}$ biorreator Controle operou sempre a $23 \pm 2^{\circ} \mathrm{C}$. Já o biorreator Teste operou sob o efeito de alterações da temperatura. Após a troca de meio, todo o conteúdo deste reator era aquecido até $40^{\circ} \mathrm{C}$, o que levava cerca de $20 \mathrm{~min}$. Assim que a temperatura atingia $40^{\circ} \mathrm{C}$, esta era mantida por mais $20 \mathrm{~min}$. Após esse tempo, esperava-se a suspensão atingir 
naturalmente a temperatura ambiente (aproximadamente 1,5 h) e repetia-se o ciclo de aquecimento/resfriamento por mais duas vezes ao longo do dia.

Condição 2. Nesta etapa o objetivo foi reproduzir as condições de operação da refinaria, empregando um regime em batelada. Para tal, foram utilizados como biorreatores dois

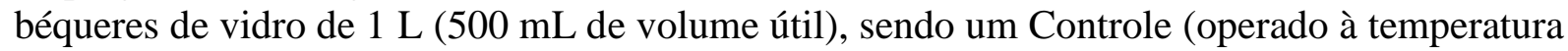
ambiente) e um Teste (com variação da temperatura). A alimentação consistia da mistura das correntes Água Ácida e Água Oleosa, juntamente com o efluente sintético de modo a se obter DQO próxima a $1000 \mathrm{mg} / \mathrm{L}$. Todos os dias (com exceção dos finais de semana) eram feitas duas trocas de meio. De manhã, desligava-se a aeração e a agitação, deixava-se o lodo sedimentar por 30 min e então metade do sobrenadante $(130 \mathrm{~mL})$ era substituída por nova alimentação de modo a simular uma razão de reciclo de 1:1. À tarde, 5,5 h (TRH do sistema em regime contínuo considerando a vazão de recirculação) após a $1^{a}$ troca de meio, retirava-se uma alíquota do licor misto para manter a idade do lodo em $20 \mathrm{~d}$ e, novamente, desligava-se a aeração e a agitação. Após sedimentação de $30 \mathrm{~min}$, todo o sobrenadante $(260 \mathrm{~mL})$ era substituído por nova alimentação para manutenção da biomassa até o dia seguinte. $\mathrm{Na}$ alíquota de licor misto retirada, analisava-se o volume de lodo sedimentado, a concentração de sólidos suspensos, o pH e a DQO centrifugada. O efeito da temperatura no biorreator Teste foi avaliado de forma diferente da Condição 1, utilizando-se efetivamente o conceito de choque térmico. Ao invés de aquecer todo o conteúdo do reator a $40^{\circ} \mathrm{C}$, aquecia-se apenas uma fração da alimentação a $97^{\circ} \mathrm{C}$. $\mathrm{Na} 1^{\mathrm{a}}$ troca de meio, $130 \mathrm{~mL}$ de alimentação aquecida eram adicionados no reator, de modo que o equilíbrio térmico fazia com que este ficasse quase de imediato a $40^{\circ} \mathrm{C}$. Na $2^{\mathrm{a}}$ troca de meio, $130 \mathrm{~mL}$ de alimentação aquecida e $130 \mathrm{~mL}$ de alimentação à temperatura ambiente eram adicionados no reator, novamente fazendo com que este ficasse a $40^{\circ} \mathrm{C}$. Após o choque térmico, a temperatura do reator era mantida ou não em $40^{\circ} \mathrm{C}$ por um tempo determinado, conforme detalhado nos resultados.

\subsection{Operação dos Biorreatores - Contínuo}

Neste estudo foram utilizados dois biorreatores de Lodos Ativados (um Controle e um Teste) cujo projeto se baseou em um modelo proposto por Ramalho (1983), que não necessita de reciclo. Os reatores apresentavam volume útil de $2,68 \mathrm{~L}$, com $1,84 \mathrm{~L}$ no compartimento de aeração e $0,84 \mathrm{~L}$ no compartimento de sedimentação. O licor misto era mantido em suspensão por meio de introdução de ar comprimido através de difusor instalado ao fundo do compartimento de aeração, separado do compartimento de sedimentação por uma placa móvel cuja abertura ao fundo do reator definia a passagem de lodo de um compartimento para o outro. Diariamente (com exceção dos finais de semana), $134 \mathrm{~mL}$ de licor misto eram retirados do reator, de modo a manter a idade do lodo em $20 \mathrm{~d}$. Como o biorreator apresentava o compartimento de sedimentação junto ao tanque de aeração, a placa de separação era retirada, todo o conteúdo do reator era homogeneizado e uma amostra representativa do licor misto era tomada. Inicialmente, a alimentação consistia de efluente sintético diluído em Água Oleosa, de modo a manter a DQO em torno de $1000 \mathrm{mg} / \mathrm{L}$. Em seguida, a Água Ácida era diluída em água destilada e suplementada com fósforo de modo a manter a relação DQO:P em 100:1. Os biorreatores operaram com TRH de $24 \mathrm{~h}$. Para a avaliação do efeito da temperatura, uma bomba peristáltica retirava o licor misto do tanque de aeração do biorreator Teste, passava por um tubo de vidro imerso em um banho a $40^{\circ} \mathrm{C}$ e retornava para o biorreator após a troca de 
temperatura. A vazão foi ajustada de modo a se obter um tempo de retenção de 20 e 12 min no banho aquecido, dependendo do período avaliado.

\subsection{Métodos Analíticos}

Os sólidos suspensos foram determinados de acordo com os métodos $2540 \mathrm{D}$ e $2540 \mathrm{E}$ (APHA, 2005) em amostras centrifugadas (2069 g / $10 \mathrm{~min}$ ) e lavadas com com água destilada. Um índice volumétrico de lodo modificado foi determinado por sedimentação de 25 $\mathrm{mL}$ de licor misto em provetas de $25 \mathrm{~mL}$ por $40 \mathrm{~min}$, servindo apenas como comparação da sedimentabilidade do lodo nos biorreatores Controle e Teste. No sobrenadante das amostras, media-se o pH e a DQO, de acordo com o método 5220 D (APHA, 2005). O Carbono Orgânico Total (COT) foi obtido por análise em aparelho Shimadzu, modelo TOC-V $\mathrm{V}_{\mathrm{CPN}} \mathrm{e}$ a respirometria foi feita no respirômetro Bioscience, modelo BI-2000. A significância dos resultados obtidos foi avaliada pelo teste $t$-Student com $95 \%$ de confiança, empregando-se o software Statistica 7.0.

\section{RESULTADOS E DISCUSSÃO}

\subsection{Operação dos Biorreatores - Batelada}

Na primeira condição avaliada em batelada (Condição 1), os biorreatores operaram por um período total de $60 \mathrm{~d}$, sendo os principais resultados apresentados na Figura 1. A remoção de DQO variou de acordo com as mudanças de composição do efluente. A corrente utilizada na alimentação dos reatores contém amônia, metais pesados, compostos sulfurados e outras substâncias que, dependendo da concentração, podem se tornar inibitórias/tóxicas e prejudicar o tratamento biológico. Em quase todo o período avaliado não houve diferença significativa na remoção de DQO. Apenas nas bateladas 22 a 33 foi observada melhor remoção no biorreator Teste $(71,4 \pm 6,0 \%)$ em relação ao Controle $(60,6 \pm 5,6 \%)$.
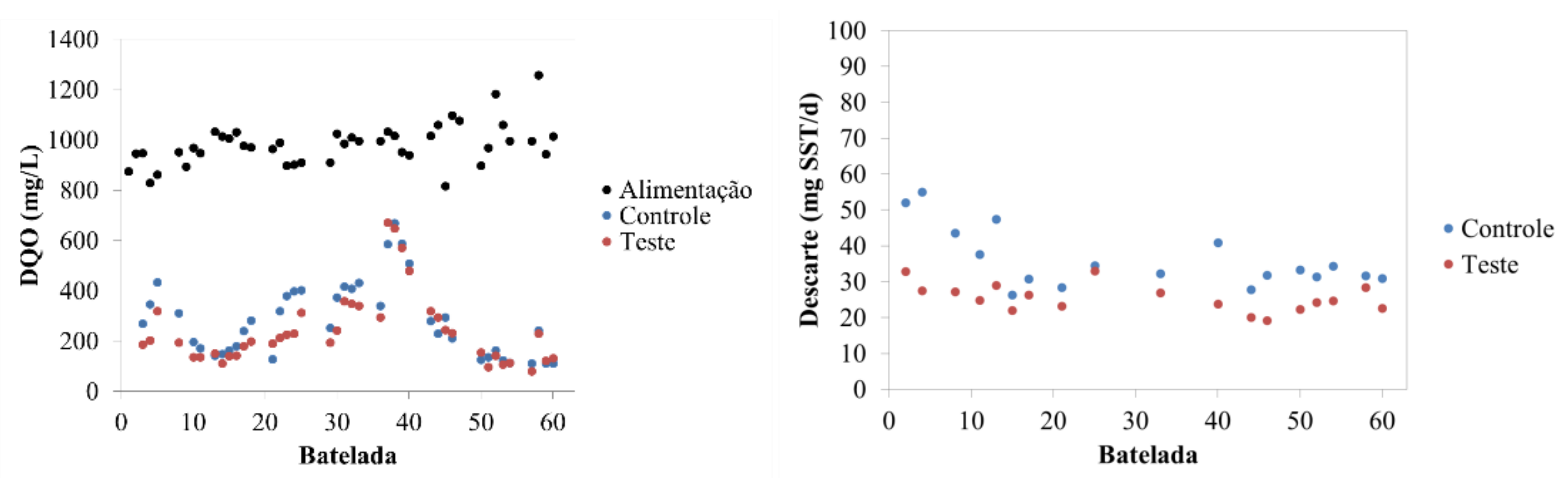

Figura 1 - Principais resultados da operação em batelada dos biorreatores (Condição 1).

Em termos de sólidos suspensos e, consequentemente, descarte, o início da operação apresentou diferença entre os valores nos dois biorreatores, no entanto os valores estabilizaram próximo da $25^{\mathrm{a}}$ batelada. Após esse período, é possível observar uma diferença significativa nos valores, levando à redução de $28,1 \%$ no descarte de lodo no período que compreende as bateladas 41 a 60 (32 $\pm 2 \mathrm{mg} \mathrm{SST/d}$ para o Controle e $23 \pm 3 \mathrm{mg} \mathrm{SST/d}$ para o Teste). Em termos de IVL, o tratamento térmico prejudicou a sedimentação do lodo. Neste 
período em que se obteve redução de $28,1 \%$ no descarte, o IVL do Controle foi de $118 \pm 17$ $\mathrm{mL} / \mathrm{g}$, enquanto no Teste foi de $224 \pm 77 \mathrm{~mL} / \mathrm{g}$, indicando que a sedimentabilidade do lodo no biorreator Teste foi pior que no Controle. Vale ressaltar também que o $\mathrm{pH}$ manteve valores próximos a 7,5 nos dois biorreatores, valor considerado adequado para o tratamento aeróbio.

Já na segunda condição estudada, os biorreatores operaram por um período total de 162 d e os resultados foram divididos com base na operação. $O$ primeiro período representa a adaptação do lodo, quando não foi avaliado o efeito da temperatura. Em seguida, os períodos se diferiram com base na quantidade de choques realizados por dia (1 choque/d refere-se ao choque apenas na $1^{\mathrm{a}}$ troca de meio e 2 choques/d refere-se ao choque na $1^{\mathrm{a}}$ e na $2^{\mathrm{a}}$ troca $\mathrm{de}$ meio). Nos períodos 2 e 3 foram realizados 1 e 2 choques, respectivamente. Nos períodos 4 e 5 , foram realizados 2 choques diários, porém a temperatura foi mantida a $40^{\circ} \mathrm{C}$ por 20 e 40 min, respectivamente. Os principais resultados encontram-se na Figura 2.
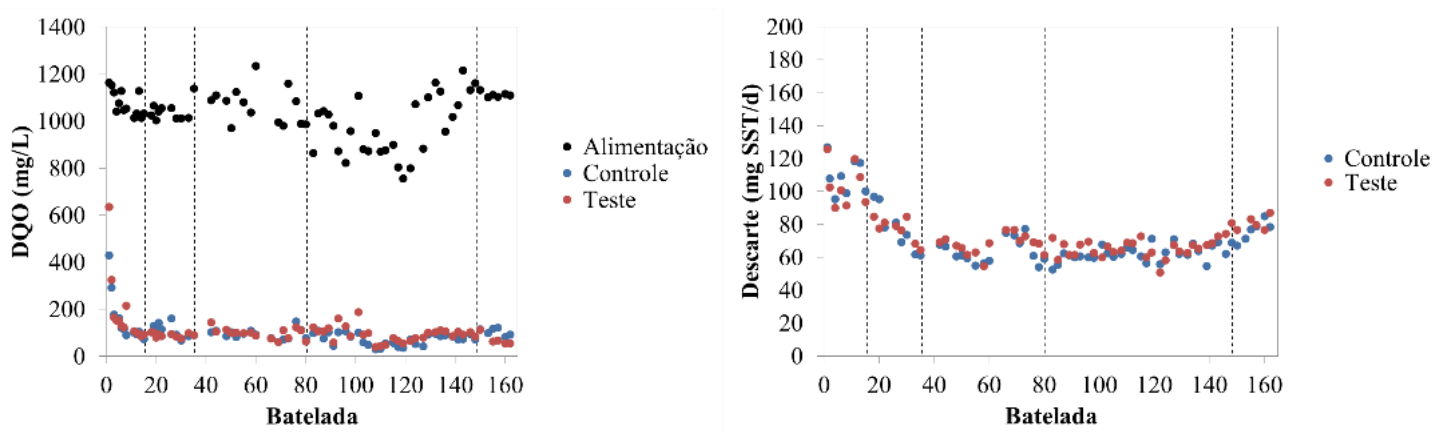

Figura 2 - Principais resultados da operação em batelada dos biorreatores na Condição 2. Bateladas 1 a 15 = adaptação do lodo; bateladas 16 a $35=1$ choque/d; bateladas 36 a $80=2$ choques/d ; bateladas 81 a $148=2$ choques $/ \mathrm{d}, 40^{\circ} \mathrm{C} / 20 \mathrm{~min}$; bateladas 149 a $162=2$ choques $/ \mathrm{d}, 40^{\circ} \mathrm{C} / 40$ min Linhas tracejadas representam diferentes períodos de operação.

Pelos gráficos da Figura 2 é possível perceber que não houve diferença significativa na remoção de DQO e no descarte de lodo nos biorreatores ao longo de todo o período, fato este comprovado pela análise estatística. As remoções de DQO foram de 90,8 \pm 4,9\% no Controle e 89,5 $\pm 6,5 \%$ no Teste. O descarte variou ao longo do tempo, e uma comparação entre os reatores no período 4 (bateladas 81 a 148), o mais extenso e estável, mostra que não houve diferença no tratamento com e sem utilização do choque térmico, pois o descarte foi de $63 \pm 5$ mg SST/d no Controle e $66 \pm 6 \mathrm{mg} \mathrm{SST/d} \mathrm{no} \mathrm{Teste.} \mathrm{Na} \mathrm{Condição} 2$ o IVL foi menor no biorreator Teste nos últimos dois períodos de operação, indicando melhor sedimentação que no Controle. No período 4, os valores de IVL foram de $146 \pm 69 \mathrm{~mL} / \mathrm{g}$ no Controle e $69 \pm 22$ $\mathrm{mL} / \mathrm{g}$ no Teste. Isso indica que formas diferentes de impor o aquecimento influenciam não só o descarte de lodo como também sua sedimentabilidade.

No $4^{\circ}$ período de operação ( 2 choques por dia, mantendo-se $40^{\circ} \mathrm{C}$ por $20 \mathrm{~min}$ ) foi feito um estudo de decaimento de DQO e COT nos biorreatores, bem como uma respirometria. Os resultados obtidos nos dois biorreatores não foram suficientes para serem avaliados estatisticamente. Assim mesmo pode-se verificar que, mesmo os resultados sendo muito próximos, que o biorreator Teste apresentou valores ligeiramente inferiores que o Controle, indicando uma cinética de degradação mais lenta. Os resultados encontram-se na Tabela 2. 
Tabela 2 - Consumo de substrato e oxigênio nos biorreatores

\begin{tabular}{lcc}
\hline \multicolumn{1}{c}{ Parâmetro } & Controle & Teste \\
\hline Constante de degradação de DQO $\left(\mathrm{h}^{-1}\right)$ & 1,6 & 1,0 \\
Constante de degradação de COT $\left(\mathrm{h}^{-1}\right)$ & 2,1 & 1,5 \\
Taxa específica de consumo de $\mathrm{O}_{2}\left(\mathrm{mg} \mathrm{O}_{2} / \mathrm{g}\right.$ SSV.h) & 463 & 437 \\
\hline
\end{tabular}

\subsection{Operação dos Biorreatores - Contínuo}

Os biorreatores operaram por um período total de 107 d, divididos em três períodos com base na operação. No primeiro período (dias 1 a 15) ambos os biorreatores operaram sem tratamento térmico de modo a adaptar o lodo ao efluente e às condições de operação. Dos dias 16 a 38, o biorreator Teste operou sob efeito da temperatura. Uma linha de reciclo fazia com que parte do licor misto do tanque de aeração passasse por um banho a $40^{\circ} \mathrm{C}$ com uma vazão ajustada para se obter um tempo de retenção nessa temperatura de $20 \mathrm{~min}$. No último período de operação (dias 39 a 107), o tratamento térmico foi realizado a $40^{\circ} \mathrm{C} \mathrm{com}$ tempo de $12 \mathrm{~min}$. Com relação à alimentação, nos períodos 1 e 2 ela consistiu de efluente sintético diluído em Água Oleosa, enquanto que no último período consistiu de Água Ácida diluída em água destilada.

Os principais resultados desta operação encontram-se na Figura 3. Não foi observada diferença significativa na remoção de DQO em nenhum período avaliado, obtendo-se valores médios de $82,6 \pm 11,9 \%$ no Controle e $81,5 \pm 14,9 \%$ no Teste. A DQO final dos biorreatores foi maior no último período de operação, mas isso se deve à mudança de alimentação, que passou a consistir de uma corrente de efluente industrial que apresenta diversas substâncias tóxicas, tais como sulfetos e metais pesados. Não houve diferença no $\mathrm{pH}$ de saída dos biorreatores, sendo observados valores médios de 7,2 $\pm 0,8$ (Controle e Teste). A concentração de sólidos suspensos e, consequentemente, do descarte diminuiu no decorrer do tempo devido à adaptação da biomassa às condições de operação, porém foi estatisticamente igual nos dois biorreatores em todos os períodos avaliados. No terceiro período de operação os valores se encontram mais estáveis, sendo observados valores médios de descarte de $154 \pm$ $25 \mathrm{mg}$ SST/d para o Controle e $152 \pm 26 \mathrm{mg}$ SST/d para o Teste.
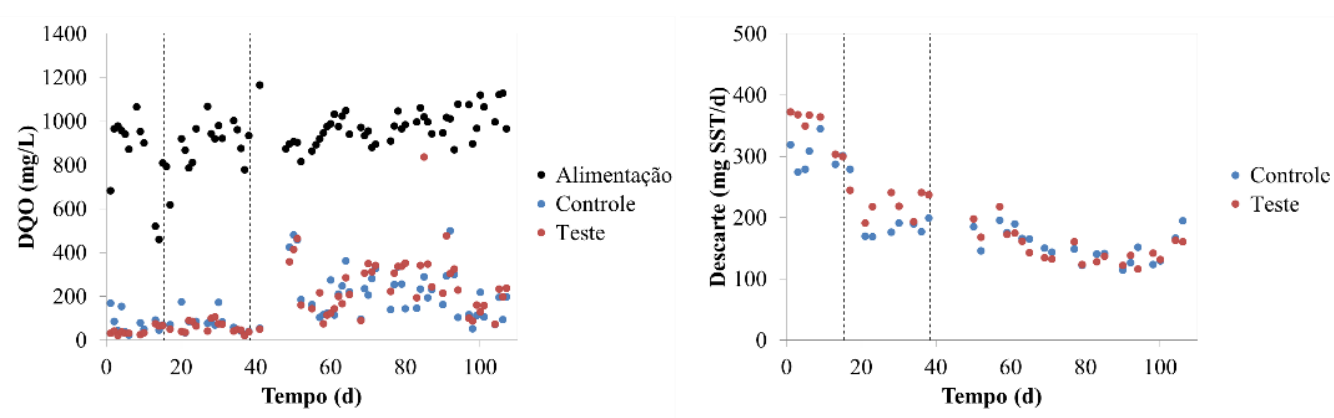

Figura 3 - Principais resultados da operação em modo contínuo dos biorreatores. Dias 1 a 15 = adaptação; dias 16 a $38=40^{\circ} \mathrm{C} / 20 \mathrm{~min}$; dias 39 a $107=40^{\circ} \mathrm{C} / 12 \mathrm{~min}$. Linhas tracejadas representam diferentes períodos de operação.

\section{CONCLUSÕES}


O tratamento térmico utilizado nos experimentos com Lodos Ativados em escala laboratorial levou a resultados variáveis. De modo preliminar, pode-se concluir que é uma tecnologia que vale ser estudada no tratamento de efluentes de refinaria de petróleo, pois levou a um descarte $28 \%$ menor que no Controle em uma das operações em batelada. Porém, o modo como o tratamento térmico é aplicado no sistema (aumento gradual da temperatura ou choque térmico) influencia o resultado obtido.

\section{REFERÊNCIAS BIBLIOGRÁFICAS}

APHA, AWWA, WEF. Standard Methods for the Examination of Water \& Wastewater. 21 ${ }^{\mathrm{a}}$ Ed., Washington, 2005.

BOTT, C. B.; LOVE, N. G. The immunochemical detection of stress proteins in activated sludge exposed to toxic chemicals. Water Research, v. 35, n. 1, p. 91-100, 2001.

BRASIL. Lei $\mathrm{n}^{\mathrm{o}}$ 12.305, 02 de agosto de 2010. Institui a Política Nacional de Resíduos Sólidos; altera a lei ${ }^{\circ} 9.605$ de 12 de fevereiro de 1998; e dá outras providências. Diário Oficial da União. Disponível em http://www.planalto.gov.br/ccivil_03/_ato20072010/2010/lei/112305.htm. Acesso em 24 de julho de 2013.

BROOKES, A. Immersed membrane bioreactors for produced water treatment. Tese de Doutorado, Cranfield University, 2005.

ENZO LIFE SCIENCES. Heat shock proteins \& the cellular stress response. Disponível em http://www.enzolifesciences.com/fileadmin/files/catalog/zz-c0210-1002_hsp_us_lowres .pdf. Acesso em 01 de outubro de 2012.

FOLADORI, P.; ANDREOTTOLA, G.; ZIGLIO, G. Sludge reduction technologies in wastewater treatment plants. IWA Publishing, Londres, 2010.

HAN, M.; YUN, H.; LEE, S. Y. Microbial small heat shock proteins and their use in biotechnology. Biotechnology Advances, v. 26, p. 591-609, 2008.

MA, H.; ZHANG, S.; LU, X.; XI, B.; GUO, X.; WANG, H.; DUAN, J. Excess sludge reduction using pilot-scale lysis-cryptic growth system integrated ultrasonic/alkaline disintegration and hydrolysis/acidogenesis pretreatment. Bioresource Technology, v. 116, p. 441-447, 2012.

METCALF \& EDDY. Wastewater engineering: treatment and reuse. $4^{\mathrm{a}}$ Ed., McGraw-Hill, 2003.

PETROBRAS. Relatório de Sustentabilidade, 2012.

RAMALHO, R. S. Introduction to wastewater treatment process. $2^{\mathrm{a}}$ Ed., Academic Press, 1983.

VON SPERLING, M. Lodos ativados. $2^{\mathrm{a}}$ Ed., $4^{\mathrm{a}}$ Reimpressão, Editora UFMG, Belo Horizonte, 2002. 